\title{
A Study of the Role of Strategy in Foreign Language Learning
}

\section{Yi-An Hou}

St. Mary's Junior College of Medicine, Nursing, and Management, Taiwan

Email: hyn@smc.edu.tw

How to cite this paper: Hou, Y.-A. (2018). A Study of the Role of Strategy in Foreign Language Learning. Open Journal of Modern Linguistics, 8, 151-175.

https://doi.org/10.4236/ojml.2018.85016

Received: August 7, 2018

Accepted: October 6, 2018

Published: October 9, 2018

Copyright (C) 2018 by author and Scientific Research Publishing Inc. This work is licensed under the Creative Commons Attribution International License (CC BY 4.0).

http://creativecommons.org/licenses/by/4.0/

\begin{abstract}
The study aimed to investigate the role of strategy in foreign language learning, including students' English learning behaviors, factors affecting students' language learning strategy use, strategies that good and poor language learners used, and to compare with that of learners of FL, ESL, and EFL. Two hundred and twenty-four Taiwanese college students served as subjects of the study. The research design was a descriptive study and the research instrument was a questionnaire of motivation, belief, strategy, and anxiety. All available data were computed by using SPSS. Findings revealed that strategy use was the best predictor of successful language learning and motivational intensity played the most significant role in influencing strategy use. In addition, good language learners used more strategies and differences of strategy use existed among learners of FL, ESL, and EFL. It's hoped to raise general awareness of language learning strategies and to bear in mind the individual difference of learners for effective teaching and learning.
\end{abstract}

\section{Keywords}

Motivation, Belief, Anxiety, Strategy, Good and Poor Language Learners, FL, ESL, EFL

\section{Introduction}

Introduction included 1) background of the study, 2) purposes of the study, and 3) research questions. They were described below:

\subsection{Background of the Study}

Studies of foreign/second language learning have experienced ever expanding growth in the interest of "Who uses what strategies where" to investigate factors dealing with the learners of FL, ESL, EFL, the strategies used, and the language 
learning setting. According to research, there are many factors affecting second/foreign language learning. Among them, some are "unchangeable", such as age, gender, aptitude, and first language; and some are "predispositions", including motivation, attitude, tolerance of ambiguity, anxiety, field independence/dependence, cognitive styles, and learning strategies (Jamieson, 1992). Much early work has been done on language learning as a cognitive work and regarded aptitude as a major role in predicting language learning success (Carroll, 1990; Carroll \& Sapon, 1959). Then, affective factor (motivation) has been thought to play a more important role than aptitude (Skehan, 1991), and has been regarded as the best predictor of subsequent achievement (Gardner, 1990). Conventionally, cognitive and affective were explored separately. Later, it is understood that to be successful in language learning, learners should have both the "skill" (language aptitude) and the "will" (motivation). And it is believed that good language learners have some characteristics in common, including cognitive and affective. Hence, the interaction of "skill" and "will" has attracted more and more attention.

In the past decades, learning strategy research has experienced tremendous growth (Nyikos \& Oxford, 1993), especially research on second/foreign language learning strategies has "burgeoned" (Oxford \& Cohen, 1992: p. 2). According to Oxford, learning strategies are "specific actions taken by the learner to make learning easier, faster more enjoyable, more self-directed, more effective, and more transferable to new situations" (Oxford, 1990b: p. 440). Furthermore, much research on language learning strategies has established their role in making language learning more efficient and effective and suggested that "strategy training in the language learning classroom can lead to greater achievement" (Young, 1995: p. 338). Hence, to improve language learning, the increasing interest of learning strategies has become one of the mainstreams since the 1990's. Consequently, the study was conducted due to the significances of learning strategies for its involving both "skill" and "will", being the key to learner autonomy, being a source of insight into the difficulties of unsuccessful learners, as well as being trainable, malleable and teachable (Bialystok \& Frohliu, 1978; Hagen et al., 1994; Oxford, 1990a; Oxford et al., 1993; Wenden, 1987).

\subsection{Purpose of the Study}

The purpose of the study was to explore the role of strategy in foreign language learning. Discussions included 1) to investigate students' English learning behaviors and English achievement, 2) to analyze what variables affect the choice of English learning strategies, 3) to explore what language learning strategies that good and poor learners use, as well as 4) to compare the strategies used by learners of foreign language (FL), English as a second language (ESL), and English as a foreign language (EFL).

\subsection{Research Questions}

The research questions included: 
1) What were Taiwanese students' English learning behaviors and achievement?

2) What factors affected students' strategy use?

3) What strategies used by good language learners and poor language learners?

4) Was there any difference of language strategy use among learners of FL, ESL, and EFL?

\section{Related Literature}

The related literature included 1) language learning strategy and 2) factors affecting strategy use, including gender, motivation, attitude, motivational intensity, belief, and anxiety. They were reviewed below:

\subsection{Language Learning Strategy}

Oxford (1990c) defined learning strategies as "Learners' actions to enhance their own learning, which usually reflect the learners' typical learning style" (p.68). According to Rubin (1975), a good language learner is "a willing and accurate guesser; has a strong, persevering drive to communicate; is often uninhibited and willing to make mistakes in order to learn or communicate; focus on form by looking for patterns; takes advantage of all practice opportunities; monitors his or her own speech and that of others; and pays attention to meaning" (pp. 45-47). It is believed that good language learners use more and better learning strategies than poor language learners (Oxford, 1989; Rubin, 1975).

Good language learners use appropriate learning behaviors or actions to help acquire, store or retrieve information so as to make learning more effective and successful (Oxford, 1990a). Bacon (1992) indicated that when students learn, they adjust their strategies to the difficulty of the inputs; they use "bottom-up" strategies for difficult input, and "top-down" strategies for less difficult one. The former refers to a linear process in which students learn from detail to whole picture, whereas the latter deals with a global process in which students learn from whole picture to detail.

Based on the theory that "the learner is a 'whole person' who uses intellectual, social, emotional, and physical resources and is therefore not merely a cognitive/ metacognitive information-processing machines" (Oxford, 1992: p. 20), Oxford (1990a) developed a strategy system that contains six sets of 12 learning behaviors including three "direct" strategy groups: memory, cognitive, compensatory; and three "indirect" strategy groups: affective, metacognitive, social. The Strategy Inventory for Language Learning (SILL) has been widely used for investigating language learners' use of strategies.

Findings indicated that high-level students used more effective strategies (Politzer, 1983). O'Malley et al. (1985) claimed that intermediate-level students tended to use more metacognitive strategies than beginning-level students. Ehrman and Oxford (1989) found that there was a relationship between learning styles and strategies, for instance, those who are labeled as thinkers used analytic strategies more frequently, while feelers preferred interpersonal, global, and social 
strategies. In Oxford and Nyikos's (1989) study, it was found that language learning strategies most frequently used by university students were formal strategies, most rule-related strategies, and general study strategies, especially for those motivated females who were more successful language learners in their study. Schiefele and Wild (1994) proposed that interest and extrinsic motivation could predict students' course achievement, but organizational and metacognitive strategies were the best predictors of successful achievement. In general, metacognitive strategies dealing with "paying attention, consciously searching for practice opportunities, planning for language tasks, self-evaluating progress and monitoring errors" (Oxford, 1992: p. 20) was the most frequently adopted for more successful language learners. Chamot (1993) developed a Learning Strategies Review Questionnaire to gather information about student reactions to the strategy instruction. The findings show that "a majority of the students believed that the strategies had a positive effect on their learning and that some students are using the strategies independently as they work on language assignment at home" (Chamot, 1993: p. 320). Oxford (1989) claimed that learners can learn more effectively by learning how to learn-strategy training. She suggested three types of strategy training: Awareness Training, One-time Strategy Training, and Long-time Strategy Training (Oxford, 1990a). In Awareness Training, participants are aware of the idea of language learning strategies and the way such strategies work, while One-time Strategy Training deals with learning and practicing one or more strategies in actual language tasks. As for Long-time Strategy Training, it includes learning, practicing, monitoring, and evaluating their own performance (Oxford, 1990a).

Oxford (1990a) developed a model for strategy training, including eight steps, of which the first five were planning and preparation steps, while the last three were conducting, evaluating, and revising the training. The model is very practical and very useful in helping students learn how to learn more effectively and efficiently.

\subsection{Factors Affecting Strategy Use}

In the study, factors affecting strategy use focused on 1) gender, 2) motivation, 3) attitude, 4) motivational intensity, 5) belief, and 6) anxiety. They were discussed as followed:

\subsubsection{Gender}

Differences between males and females are found existing in motivation, attitude, strategy, learning styles, achievement motivation, attribution, self-efficacy, goal-setting, language achievement, and many others. It was found that females are more motivated (Gardner \& Lambert, 1972; Liu, 1973; Oxford \& Nyikos, 1989), have more positive attitude toward language learning (Gardner \& Lambert, 1972), are more sensitive to criticism, respond differently to success and failure (Franken, 1982), are concerned with their academic performance, likely to choose effort attributions (Leung et al., 1993), need continuing social approval 
(Bardwick, 1971), but tend to avoid skill tasks, respond less positively to intellectual challenge, and have lower expectations for success at intellectual tasks than males. All have influenced females' choice of language learning strategy to some extent.

In nature, females are more skilled in using learning strategies to learn new language (Oxford et al., 1993), and "if necessary, to change their approach to the learning" (Prokop, 1989: p. 86). On the contrary, males show different patterns of accepting or rejecting certain learning strategies (Prokop, 1989). It was found that males had greater visual-spatial acuity (Nyikos, 1990), and like to engage in learning which was more risk-taking or creative (Prokop, 1989). Findings showed that females tend to have stronger social orientation than males (Oxford, 1989; Politzer, 1983), which may provide the explanation of females' use more learning strategies, such as social strategies (Ehrman \& Oxford, 1989); cognitive strategies, social strategies, and affective strategies (Oxford et al., 1993); formal rule-based practice strategies, general study strategies and conversational input elecitation strategies (Oxford \& Nyikos, 1989); as well as a more systematic and cautions Rational Approach (Prokop, 1989).

In typical language learning situation, females are superior in verbal ability, more cooperative on both tests of receptive and productive skills, use more social and communicative learning strategies (Ehrman \& Oxford, 1989), female students generally have better achievement than male students in language learning (Lai, 1977; Leung et al., 1993; Liu, 1973; Oxford et al., 1993). But it was found that some differences of strategy use can be decreased or improved by language strategy training (Nyikos, 1990).

\subsubsection{Motivation}

Gardner \& Lambert (1959) were the first to introduce the integrative-instrumental approach to measuring motivation. Attention was shifted from the study of learner's behavior to the learning process of language learners. It was this shift that gave definition to the field of second/foreign language learning (Larsen-Freeman \& Long, 1991), but the seeds of the distinction between instrumental motivation and integrative motivation were cultivated earlier. Integratively motivated learners are those who wish to identify with another ethnolinguistic group, whereas instrumentally motivated learners are those who learn a second/foreign language for utilitarian purposes. As for the effects of orientations on the use of language learning strategies, in Prokop's (1989) study, it was found that students with an instrumental motivation showed a significant difference in the use of language learning strategies. Oxford (1990c) pointed out that "purely instrumentally language learners used more analytical rule learning skills to fulfill the academic requirements and to earn good grade in a relatively traditional academic environment" (pp. 99-100). But Politzer (1983) found that little evidence existed for a link between language strategies use and motivational orientations.

In addition to reasons for learning another language, language learning goals 
also play an important role in determining strategy use (Politzer \& McGroarty, 1985). For example, language learners with the goal of developing aural/oral communication skills may use strategies different from learners whose learning goal is to develop reading or writing skills. Even instrumentally motivated learners do not necessarily use similar learning strategies. It was found that students learn a foreign language for career reasons used communication-oriented strategies which was in contrast to those of students whose goals were toward grade (Ehrman \& Oxford, 1989; Oxford, 1986).

\subsubsection{Attitude}

Attitude is tied up with motivational dynamics, especially in mastery learning of a foreign language (Titone, 1990). The answer to the question whether there is a liner, causal perspective on the attitude-proficiency relationship is inconsistent and contradictory. But Gardner (1979) claimed that attitude did play an important role in foreign language learning though it did not affect achievement directly. As for its contribution to the use of learning strategies, Oxford (1990a) explained that attitudes are likely to influence the choice of strategies. In Bialystok \& Frohlich's (1978) study, it was found that strategy use and attitude were related as were aptitude and Field Independence, but only aptitude and strategy use affect achievement. Later, Bialystok (1983) found that learner's attitude was highly influential in strategy use, more influential than language aptitude.

Attitudes toward a target language are not inborn (Titone, 1990); they can be learned and changed (Genesee, 1983) and can be influenced more readily than can cognitive aptitude factors (Mantle-Bromley \& Miller, 1991) by such variables as parents, peers, learning situation, teachers, ethnicity, and the like (Larsen-Freeman \& Long, 1991). Hence, it is believed developing positive attitudes is the first step toward foreign language proficiency. Wenden (1987) pointed out that no amount of learning strategy training will be effective, unless negative attitudes toward learner's self-direction are changed. In that case, language teachers play an important role in the sound attitude developing process.

\subsubsection{Motivational Intensity}

Motivational intensity is determined by the amount of effort and enthusiasm the students display in their attempt to learn the target language. Motivational intensity is a key determinant of frequency and type of strategy use (Oxford \& Nyikos, 1989). Oxford \& Nyikos (1989) found that except for Factor 4: Resourceful independent strategy (cognitive, memory, metacognitive), motivational levels had the most powerful influence on students' use of learning strategies. Students with high motivational intensity used the rest strategies (formal rule-related practice strategy, functional practice strategy general study strategy, and conversational/input elicitation strategy) more often than students with low motivational intensity. Oxford et al. (1993) claimed that the more frequently the student used the language learning strategies, the more motivated the student became, at the same time, the more the student became motivated, the more 
often the student used the language learning strategies. Furthermore, the more motivated the student and used learning strategies more often had better language achievement (Oxford et al., 1993).

\subsubsection{Belief}

The effect of learners' beliefs about language learning on their choice of language learning strategies has been widely supported. Horwitz (1985) even found that students' beliefs also linked to motivation, in addition to many findings that claimed students' beliefs are crucial, directly affect the way students use learning strategies (Nyikos \& Oxford, 1993; Oxford \& Nyikos, 1989), determine types of strategies use (Horwitz, 1985, 1988; Oxford, 1990a), as well as concluded that there is a connection between learners' belief about language learning and their choice of language learning strategies (Horwitz, 1987, 1988; Wenden, 1987). In addition, not only students' beliefs are relative to their learning but also teachers' beliefs have impacts on students' anxiety and strategy use (Hou, 2015; Hou et al., 2012, 2015b). For example, comparing with American teachers, many Chinese teachers tend to emphasize more on the importance of correct grammar, good pronunciation, and immediate error correction, consequently, Chinese students are more anxious than American students about feeling overwhelmed by the number of rules, and tend to use Memory Strategy more (Hou, 2015; Hou et al., 2012, 2015b). Horwitz's (1988) Beliefs about Language Learning Inventory (BALLT) has been widely adopted as the instrument to examine students' beliefs about second/foreign language learning.

\subsubsection{Anxiety}

Learning is "the process of acquiring relative permanent change in understanding, attitude, knowledge, information, ability, and skill through experience" (Wittrock, 1977: p. ix), and during the learning process, anxiety may occur anytime and affect learning performance, especially many learners regard foreign language learning as an anxiety-provoking experience which affects their language performance in one way or another. In fact, learning anxiety is "a distinct complex of self-perceptions, belief, feelings, and behaviors related to classroom language learning" (Horwitz, Horwitz, \& Cope, 1986: p. 28). According to Horwitz et al. (1986), it includes anxiety of communication apprehension, fear of negative evaluation, and test anxiety, and which is likely to arouse in language learning stages: input, processing, and output (Tobias, 1983) and affect language learners' performance. In addition, MacIntyre (1995) claimed that "language learning is a cognitive activity that relies on encoding, storage, and retrieval process, and anxiety can interfere with each of these ..." (p. 96). Language learning anxiety's effect on language learning is two-fold: positive and negative. In terms of its positive effect, it's believed that some anxiety can improve performance (Albert \& Habo, 1960; Scovel, 1978), and influence both the quality of performance and the amount of effort invested in it (Eysenck, 1979). On the other hand, anxiety tends to be relative to some other variables such as motivation, 
attitude, strategy use, and language learning outcome (Horwitz \& Young, 1991a; Trylong, 1987). Particularly, it has been supported that comparing with non-anxious or low-anxious students, students who suffer from foreign language anxiety tend to become more defensive and offensive, and reluctant to participate in activities that could improve their language skills and are unwilling to try affective learning strategies (Hou, 2015; Hou et al., 2012, 2015b).

In short, "Who uses what strategies where?" is a major concern when investigating language learning strategies. What factors influence students' strategies change over time (Chesterfield \& Chesterfield, 1985), and "there is no single most common pattern of strategy use across all groups" (Oxford, 1990c: p. 93), but it will be always true that the more motivated the learner is, the more appropriate learning strategies the learner will use, and use them more frequently and efficiently.

\section{Methodology}

Methodology included 1) research design, 2) sources of data, 3) procedure, and 4) Ethical consideration. They were described below:

\subsection{Research Design}

The research design was a descriptive study. The methodology of descriptive study was chosen as the research design because of its particular strength and advantages in being able to set an objective "to determine the factors, and relationships among the factors that have resulted in the current behavior or status of the study" (Gay, 1992: p. 236). All available data were computed by using SPSS (Statistical Package for the Social Science, 18.0).

\subsection{Sources of the Data}

Two hundred and twenty-four college students in south Taiwan served as subjects of the study. They were the whole freshmen of the eight departments in the college, including 209 males and 15 females. They helped to complete the questionnaire including Personal background, Motivation/Attitude Inventory for English Learning (Gardner, 1985); The Beliefs About Language Learning Inventory (Horwitz, 1988); Strategy Inventory for Language Learning (Oxford, 1989); and The Foreign Language Classroom Anxiety Scale (Horwitz, Horwitz, \& Cope, 1986). Data gathered from the above sources were used to analyze students' English learning motivation and attitude, strategies, belief, and anxiety. In addition, students' academic English grades on file were used as their English achievement, and were used to define good language learners (top ten percent) and poor ones (bottom ten percent), as well as to find out what factors relative to their English achievement.

Expecting to make for a more effective analysis of the data, some items were categorized as some factors rather than individual items. For example, items of motivation were divided into instrumental orientation and integrative orientation; 
attitude was categorized as five factors (Importance of English, Desire to learn English, Association with English, Cultural aspects, and Mechanics of learning); belief, four (Self-Efficacy, Perceived Value, Beliefs about Aptitude, and Beliefs about Formal Structural Studies); strategy, two sets of six factors each (Form A: Memory, Cognitive, Compensation, Metacognitive, Affective, and Social; Form B: Functional-Practice, Cognitive-Memory, Metacognitive, Formal-Oral Practice, Social, and Compensation), and anxiety, three (communication apprehension, test anxiety, and fear of negative evaluation). The categorized item of the questionnaire was displayed in Table 1.

\subsection{Procedure}

The theoretical framework focused on reviewing literature about second/foreign language learning, exploring how research interest has shifted from cognitive factor (language aptitude) to affective factors (motivation and attitude), and then to both cognitive and affective one (learning strategy). In addition, with an aim to investigate students' English learning behavior, a set of questionnaires of motivation, belief, strategy and anxiety was used as the research instrument. Furthermore, findings of the study were compared with that of other studies of learners of FL, ESL, and EFL.

\subsection{Ethical Consideration}

The participating students were informed about the purposes of the study in advance. They were guaranteed that the data would only be used for the study, and if they didn't feel comfortable to answer, they didn't need to sign their names on the questionnaire forms. With full understanding of the researcher's intention to conduct the study and with their full support, the data were all available.

\section{Findings and Results}

Findings included 1) reliability of the research instrument, 2) students' English learning behaviors and their English achievement, 3) factors affecting students' strategy use, strategy used by good and poor language learners, and 4) comparisons of strategy use of learners of FL, ESL, and EFL.

\subsection{Reliability of the Research Instrument}

A questionnaire was used as the research instrument. In addition to demographic information about students' background, the questionnaire included other four parts: Motivation/Attitude Inventory for English Learning (Gardner, 1985), Beliefs about Language Learning Inventory (Horwitz, 1988), Strategy Inventory for Language Learning (Oxford, 1990a), and Foreign Language Classroom Anxiety (Horwitz, Horwitz, \& Cope, 1986). The reliability of each part of the questionnaire was $.80, .81, .85, .83, .97$, and .84 for motivation, attitude, motivational intensity, belief, strategy, and anxiety, respectively. The reliability of each part was displayed in Table 2. 
Table 1. Categorized items of the questionnaire.

\begin{tabular}{|c|c|c|}
\hline Description & Factor & Item no \\
\hline Background & Gender, ways to practice English skills & $1-8$ \\
\hline \multirow{3}{*}{ 1. Motivation } & 1. Instrumental Orientation & $1,3,5,7,9,11,13,15$ \\
\hline & & \\
\hline & 2. Integrative Orientation & $2,4,6,8,10,12,14,16$ \\
\hline \multirow{5}{*}{ 2. Attitude } & 1. Importance of English & $1,2,3$ \\
\hline & 2. Desire to learn English & $4,5,11$ \\
\hline & 3. Association with English & $7,8,9,10,13$ \\
\hline & 4. Cultural aspects & $6,12,14,15$ \\
\hline & 5. Mechanics of learning & $16,17,18,19,20$ \\
\hline \multirow{4}{*}{ 3. Belief } & 1. Self-Efficacy & $4,5,6,13,16,21$ \\
\hline & 2. Perceived Value & $1,3,7,8,9,12,14,18,20,24,29,31,32$ \\
\hline & 3. Beliefs about Aptitude & $2,10,11,19,30,33$ \\
\hline & 4. Beliefs about Formal Structural Studies & $15,17,22,23,25,26,27,28,34,35$ \\
\hline \multirow{12}{*}{ 4. Strategy } & (A) 1. Memroy & $1-9$ \\
\hline & 2. Cognitive & $10-23$ \\
\hline & 3. Compensation & $24-29$ \\
\hline & 4. Metacognitive & $30-38$ \\
\hline & 5. Affective & $39-44$ \\
\hline & 6. Social & $45-50$ \\
\hline & (B) 1. Functional-Practice & $13-18,22-23,30-31,35-36,40,49-50$ \\
\hline & 2. Cognitive-Memory & $1-5,7,9,19-21$ \\
\hline & 3. Metacognitive & $8,33-34,37-39,41-44$ \\
\hline & 4. Formal-Oral Practice & $10-12,29,32$ \\
\hline & 5. Social & $45-48$ \\
\hline & 6. Compensation & $6,24-28$ \\
\hline \multirow{3}{*}{ 5. Anxiety } & 1. Communication apprehension & $1,4,9,14,15,18,24,27,29,30,32$ \\
\hline & 2. Test anxiety & $\begin{array}{c}3,5,6,8,10,11,12, \\
16,17,20,21,22,25,26,28\end{array}$ \\
\hline & 3. Fear of negative evaluation & $2,7,13,19,23,31,33$ \\
\hline
\end{tabular}

Sources: 1 \& 2. Gardner (1985). 3. Horwitz (1988). Oxford (1990a). 5. Horwitz, Horwitz, \& Cope (1986).

Table 2. Reliability of the questionnaire.

\begin{tabular}{rcccccc}
\hline & Motivation & Attitude & Intensity & Belief & Strategy & Anxiety \\
\hline Item No & 16 & 20 & 10 & 35 & 50 & 33 \\
Reliability & .80 & .81 & .85 & .83 & .97 & .84 \\
\hline
\end{tabular}




\subsection{Students' English Learning Behaviors and English Achievement}

By calculating their self-reported scores of items of instrumental orientation (odd numbered items) and integrative orientation (even numbered items), students were categorized as instrumentally motivated group (the former score was higher than the latter), integratively motivated group (the former score was lower than the latter), and balanced group (two scores were equal). Findings revealed that the majority of the students $(96.4 \%)$ were motivated more instrumentally, while $.9 \%$, more integratively, and the rest (2.7\%), balanced. However, there was no significant difference on students' English learning behaviors and English achievement among students with different orientations. In addition, it was found that factors affecting students' English achievement were 1) motivational intensity, 2) strategy use, 3) anxiety, 4) gender, 5) chances for reading, and 6) chances for writing.

Findings revealed that students with higher motivational intensity had better English achievement. In this study, $74 \%$ of the students belonged to Medium level of motivational intensity. It was found that the more strategies students used, the better English achievement they had. In addition, anxiety was found to be negatively related to English achievement $(\mathrm{T}=-2.77)$. In other words, students with higher language anxiety had lower English achievement. Furthermore, female students had better English achievement $(M=89.6 / 100)$ than male students $(M=77.8 / 100)$. Additionally, significant differences existed in Chances for reading $(\mathrm{T}=2.63, \mathrm{Sig}=.01)$ and writing $(\mathrm{T}=2.45, \mathrm{Sig}=.02)$. Students who reported to have more chances for English reading and writing had better English achievement. It was found that among the six factors affecting English achievement, strategy use was the strongest predictor of successful English achievement $(\mathrm{T}=4.96 \mathrm{Sig}=.00)$. Results of factors affecting English achievement were presented in Table 3.

\subsection{Factors Affecting Strategy Use}

Factors affecting strategy use were found to be motivation (orientations), attitude, motivational intensity, belief, anxiety, English achievement, and methods for English speaking. Among them, motivational intensity had the strongest influence on strategy use $(\mathrm{T}=14.32$, Sig $=.00)$, followed by motivation (orientations), and anxiety, negatively. The findings were shown in Table 4.

\subsubsection{Motivation (Orientations)}

Majority of the students (96.4\%) were found to be motivated to learn English more instrumentally. There was no significant difference in overall strategy use among students with different orientations (instrumental, integrative, and balanced). Yet, instrumentally motivated students tended to use more compensation Strategy or Formal-Oral Strategy, and less Affective Strategy or Metacognitive Strategy, while balanced students used more Metacognitive Strategy or Formal-Oral Strategy, and less Cognitive Strategy or Functional-Oral Strategy, 
Table 3. Factor affecting English achievement.

\begin{tabular}{ccccccc}
\hline & Intensity & Strategy & Anxiety & Gender & Reading & Writing \\
\hline $\mathrm{T}$ & 4.81 & 4.96 & -2.77 & 3.73 & 2.63 & 2.45 \\
$\mathrm{Sig} \mathrm{T}$ & .00 & .00 & .01 & .00 & .01 & .02 \\
Rank & $(2)$ & $(1)$ & $(4)$ & $(3)$ & $(5)$ & $(6)$ \\
\hline
\end{tabular}

Table 4. Factors affecting strategy use.

\begin{tabular}{cccccccc}
\hline & Motivation & Attitude & Intensity & Belief & Anxiety & Achievement & $\begin{array}{c}\text { Methods for } \\
\text { speaking }\end{array}$ \\
\hline $\mathrm{T}$ & 8.47 & 5.21 & 14.32 & 4.79 & -6.22 & 2.33 & -2.03 \\
Sig T & .00 & .00 & .00 & .00 & .00 & .02 & .04 \\
Rank & $(2)$ & $(4)$ & $(1)$ & $(5)$ & $(3)$ & $(6)$ & $(7)$ \\
\hline
\end{tabular}

Note. Methods of speaking English included 1. speaking to foreigner 2. speaking to relative 3.speaking to classmate 4. speaking to teacher 5. singing English songs.

whereas integratively motivated students used more Memory Strategy or Cognitive Strategy and lass Affective Strategy or Metacognitive Strategy.

\subsubsection{Attitude}

The findings revealed that a significant difference existed in strategy use among students with different attitudes. First, students recognizing the importance of English (Factor 1) used more Metacognitive Strategy or Compensation Strategy, less Social Strategy or Affective Strategy. Second, student with desire to learn English (Factor 2) used more Compensation Strategy or Formal-Oral Strategy, less Affective Strategy or Functional-Practice Strategy. Third, students with association with English (Factor 3) used more Compensation Strategy or Formal-Oral Strategy, less Affective Strategy or Functional-Practice Strategy. Fourth, students valuing cultural aspect (Factor 4) used more Metacognitive Strategy or Formal-Oral Strategy, less Memory Strategy or Cognitive Strategy. Last, students expecting chances for mechanics of English learning (Factor 5) used more Compensation Strategy or Social Strategy, less Affective Strategy or Metacognitive Strategy.

In terms of each kind of strategy use, a significant difference existed among students with different attitude. For example, students recognizing the importance of English (Factor 1) used Metacognitive Strategy more often than students with other attitudes, while students valuing cultural aspects (Factor 4) used other strategies much more frequently than students holding other attitudes.

\subsubsection{Motivational Intensity}

In the study, motivational intensity was divided into three levels: scores 1.0 1.6/3 (low); 1.7 - 2.3/3 (Medium) and 2.4 - 3.0/3 (High); and about $14 \%$ of the students were grouped as low level, $74 \%$ were medium level, while $12 \%$ were high level. Findings revealed that students with higher level of motivational intensity used more strategies than their counterparts. 
In particular, findings revealed that students with low motivational intensity used more Compensation Strategy or Social Strategy, less Cognitive Strategy. Additionally, students with medium motivation intensity used more Compensation Strategy or Form-Oral Strategy, less Affective strategy or Functional Practice Strategy. Furthermore, students with high motivational intensity used more Metacognitive Strategy or Formal-Oral Strategy, less Affective Strategy or Metacognitive Strategy.

\subsubsection{Belief}

For a more effective analysis of the data, items of belief were ground into four related categories. These four categories were 1) Self-Efficacy and Expectation about Learning English (Factor 1), 2) Perceived Value and Nature of Learning Spoken English, including items (factor 2), 3) Belief about Foreign Language Aptitude (Factor 3), and 4) Beliefs about Formal-Structural Studies (Factor 4).

Among the four categories, it was found that Self-Efficacy and Expectation about Learning English (Factor 1) along with Perceived Value and Nature of Learning Spoken English (Factor 2) significantly related to strategy use.

Findings showed that although there was no significant difference in every separated strategy use among students with different beliefs, yet, students with Self-Efficacy and Expectation about Learning English (Factor 1) used more Memory Strategy or Social Strategy, but less Cognitive Strategy or Functional-Practice Strategy. In addition, students with Perceived Value and Nature of Learning Spoken English (Factor 2) used more Compensation Strategy or Formal-Oral Strategy, but less Affective Strategy or Metacognitive Strategy. Furthermore, students with Beliefs about Foreign Language Aptitude (Factor 3) used more Compensation Strategy or Social Strategy, less Cognitive Strategy or Functional-Practice Strategy; and students with Beliefs about Formal Strategy studies (Factor 4) used more Compensation Strategy or Formal-Oral Strategy, but less Affective Strategy or Functional Practice Strategy.

\subsubsection{Anxiety}

Students were categorized as learners of low anxiety $(\mathrm{M}=1-2.3 / 5)$, medium anxiety $(M=2.4-3.7 / 5)$, and high anxiety $(M=3.8-5 / 5)$. In the study, the majority of the students (89.5\%) were found to be learners of medium anxiety, while one tenth (10\%), low anxiety, and the rest (0.5\%), high anxiety. Findings showed that there was a significant difference in strategy use among students with different levels of anxiety. It was found that low anxiety students used more strategies than that of medium and high anxiety students. Among the six language learning strategies, low and medium anxiety students used more compensation strategy (or Formal-Rule Strategy), while high anxiety students used Affective Strategy (or Metacognitive Strategy) more.

\subsubsection{English Achievement}

Students' English achievement was found to be positively related to their strategy use $(\mathrm{T}=4.96$, Sig $\mathrm{T}=.00)$. In other words, the better English achievement the 
students had, the more strategies they used.

\subsubsection{Methods for English Speaking Practice}

Students were required to self-report the methods they used to practice their English skills of listening, speaking, reading, writing, and translation. Among them, only the method for speaking was found to be relative to their strategy use $(\mathrm{p}<.05)$, negatively. There were five options to the question, including 1$)$ speak with foreigners, 2) speak with friends/relatives, 3) speak with classmates, 4) speak with teachers, and 5) sing English songs. Findings showed that among students choosing different methods to practice their English speaking, a significant difference existed in strategy use, especially in Compensation Strategy, Metacognitive Strategy, and Social Strategy. In particular, students reporting to "speak to foreigners" used more strategies than that of others.

In terms of individual strategy use, it was found that students reporting to "speak to foreigners", "friends/relatives", and "teachers" use Metacognitive Strategy more, while those reported to "speak to classmates" or "sing English songs" used Compensation Strategy more. On the other hand, the strategies which were used the least were Memory Strategy or Cognitive Strategy for students reporting to "speak to foreigners", Function-Practice for students adopting the rest four methods to practice English speaking.

\subsection{Strategies Used by Good Language Learners and Poor Language Learners}

The findings revealed that strategies all students used more were, in order, Compensation Strategy $\left(1^{\text {st }}\right)$, Metacognitive Strategy $\left(2^{\text {nd }}\right)$, Social Strategy $\left(3^{\text {rd }}\right)$, Memory Strategy $\left(4^{\text {th }}\right)$, Cognitive Strategy $\left(5^{\text {th }}\right)$, and Affective Strategy $\left(6^{\text {th }}\right)$ (for Form A), or Formal-Oral Practice Strategy $\left(1^{\text {st }}\right)$, Compensation Strategy $\left(2^{\text {nd }}\right)$, Social Strategy $\left(3^{\text {rd }}\right)$, Cognitive-Memory Strategy $\left(4^{\text {th }}\right)$, Metacognitive Strategy $\left(5^{\text {th }}\right)$ and Functional-Practice Strategy $\left(6^{\text {th }}\right)$ (for Form B). The mean of strategies used by all students is $\mathrm{M}=3.03 / 5$ ( $\mathrm{SD}=.69$ ).

Based on their academic English grades, the top ten percent of the students were categorized as good language learners $(\mathrm{N}=21)$, while the bottom ten percent as poor language learners $(\mathrm{N}=24)$. It was found that good language learners and poor language learners used many strategies, but the former use strategies much more frequently than the latter. As far as individual strategy was concerned, the strategies that both good language learners and poor language learners used most were the same, which was Compensation Strategy (both Form A and Form B). The strategy that good language learners used least was Affective Strategy (Form A) or Metacognitive Strategy (Form B), while Cognitive Strategy (Form A) or Social Strategy (Form B) was used least by poor language learners. The mean of strategy used by good learners and poor learners was $M=3.27 / 5$ $(\mathrm{SD}=.57)$ and $\mathrm{M}=2.51 / 5(\mathrm{SD}=.73)$, respectively. The findings were presented in Table 5(a) and Table 5(b). 
Table 5. Order of strategies used by good and poor language learners (a) (b).

(a)

\begin{tabular}{cccccccccc}
\hline & N & Memor & Cogni & Compen & Meta & Affec & Socia & M & SD \\
\hline Good & 21 & 3rd & 4 th & 1 st & 2nd & 6 th & 5 th & 3.27 & .57 \\
Poor & 24 & 3rd & 6 th & 1 st & 2nd & 4 th & 5 th & 2.51 & .73 \\
All & 224 & 4 th & 5 th & 1st & 2nd & 6 th & 3rd & 3.03 & .69 \\
\hline
\end{tabular}

Note: All = All subjects of the study; Good $=$ top 10\% of the subjects for their English scores; Poor $=$ bottom $10 \%$ of the subjects for their English scores; 1st - 6th = order of strategy used from the most to the least; Memor = memory strategy; Cogni $=$ cognitive strategy; Compen $=$ compensation strategy; Meta = metacognitive strategy; Affec = affective strategy; Soci = social strategy.

(b)

\begin{tabular}{cccccccccc}
\hline & $\mathrm{N}$ & Funct & Cognit & Metacog & Formal & Social & Compen & M & SD \\
\hline Good & 21 & 5 th & 4 th & 6 th & 1 st & $2^{\text {nd }}$ & 3 rd & 3.27 & .57 \\
Poor & 24 & 4 th & 5 th & 3 rd & 1 st & $6^{\text {th }}$ & 1 st & 2.51 & .73 \\
All & 224 & 6 th & 4 th & 5 th & 1 st & $3^{\text {rd }}$ & 2 nd & 3.03 & .69 \\
\hline
\end{tabular}

Note: All = All subjects of the study; Good $=$ top $10 \%$ of the subjects for their English scores; Poor $=$ bottom $10 \%$ of the subjects for their English scores; 1st - 6th = order of strategy used from the most to the least; Funct $=$ functional-practice strategy; Formal $=$ formal strategy; Cognit $=$ cognitive-memory strategy; Social = social strategy; Metacog = metacognitive strategy; Compen = compensation.

In addition, it was found that except for motivation (orientations), significant differences existing in attitude, motivational intensity, belief, strategy, and anxiety. Findings showed that, except for anxiety, good language learners had higher mean in such variables as attitude, motivational intensity, belief, and strategy than that of poor language learners. In other words, comparing with poor language learners, good language learners significantly held more positive attitude and belief toward English learning, had stronger motivational intensity, used more strategies, and tended to be less anxious in English learning than poor language learners. The findings were displayed in Table 6.

\subsection{Comparisons of Language Learning Strategy Use among Learners of FL, ESL, and EFL}

In comparison with other studies investigating language learning strategies used by learners of Foreign Language (FL), English as a Second Language (ESL), and English as a Foreign Language (EFL), some similarities and differences did exist. To take the following three studies with mean or rank of each strategy as examples, 1) Oxford \& Nyiko (1989) (FL), subjects were American college students learning Russian, French, Spanish, Italian, and German as a foreign language; 2) Oxford et al. (1990) (ESL), subjects were learners in an intensive program at Pennsylvania State University; and 3) Young (1993) (EFL), subjects were students in college and in an intensive English program in Taiwan, findings showed that for EFL learners (Young, 1993 and the present study), the most frequently used strategy was Compensation Strategy, while Social Strategy was the most frequently used by ESL learners (Oxford et al., 1990) (see Table 7(a)) (Form A), 
Table 6. Differences in variables between good learners and poor learners.

\begin{tabular}{ccccccccc}
\hline & $\mathrm{N}$ & & Motivation & Attitude & Intensity & Belief & Strategy & Anxiety \\
\hline \multirow{2}{*}{ Good } & 21 & $\mathrm{M}$ & 3.74 & 3.77 & 2.40 & 3.71 & 3.27 & 2.28 \\
& & $\mathrm{SD}$ & .54 & .57 & .35 & .23 & .57 & .52 \\
\multirow{2}{*}{ Poor } & 24 & $\mathrm{M}$ & 3.68 & 3.34 & 1.90 & 3.54 & 2.51 & 3.08 \\
& & $\mathrm{SD}$ & .50 & .49 & .31 & .23 & .73 & .44 \\
F Prob & & & .2392 & .0120 & .000 & .0281 & .0004 & .0000 \\
\hline
\end{tabular}

Note: Good = students with top 10\% of English achievement $(n=21)$; Poor $=$ students with bottom $10 \%$ of English achievement $(\mathrm{n}=24)$.

Table 7. Comparisons among language learners' use of strategies (a) (b).

(a)

\begin{tabular}{ccccc}
\hline & EFL $^{*}$ & EFL $^{* *}$ & EFL $^{* * *}$ & ESL \\
\hline Memory & 4 th & 6 th & 6 th & 6 th \\
Cognitive & 5 th & 5 th & 5 th & 3 rd \\
Compensation & 1 st & 1 st & 1 st & 4 th \\
Metacognitive & 2nd & 3 rd & 4 th & 2 nd \\
Affective & 6 th & 2 nd & 3 rd & 5 th \\
Social & 3 rd & 4 th & 2 nd & 1 st \\
N & 224 & 515 & 86 & 43 \\
\hline
\end{tabular}

Note: $\mathrm{EFL}^{*}=$ Subjects were college students in Taiwan of the study. $\mathrm{EFL}^{* *}=$ Subjects were college students in Taiwan (Young, 1993). $\mathrm{EFL}^{\star \star \star}=$ Subjects were students in an intensive English program in Taiwan (Young, 1993). ESL = Subjects were learners in the intensive program at Pennsylvania State University (Oxford, et al.'s study in 1990).

(b)

\begin{tabular}{ccccc}
\hline & EFL $^{*}$ & EFL $^{* *}$ & & FL \\
\hline Functional & 6 th & 5 th & Functional & 5 th \\
Cognitive-Memory & 4 th & 6 th & Cognitive & \\
Metacognitive & 5 th & 4 th & Metacognitive & 4 th \\
Formal-Oral & 1 st & 1 st & Formal-Rule & 1 st \\
Compensation & 2 nd & 2 nd & Compensation & 3 rd \\
Social & 3 rd & 3 rd & Social & 2nd \\
& & & General Study & 1200 \\
\hline
\end{tabular}

Note: $\mathrm{EFL}^{*}=$ Subjects were college students in Taiwan of the study; $\mathrm{EFL}^{\star *}=$ Subjects were college students in Taiwan (Young's study in 1993); FL = Subjects were American college students learning Russian, French, Spanish, Italian, and German as a foreign language (Oxford \& Nyiko's study in 1989).

and the least used strategy for EFL (Young, 1993) and ESL (Oxford et al., 1990) was Memory Strategy, while it was Affective Strategy for the present study (Form A). In addition, Formal-Oral Strategy was the most frequently used by all 
the EFL (Young, 1993), FL (Oxford \& Nyiko, 1989) (Form B), and the present study, whereas Functional Strategy, Cognitive-Memory Strategy, and Metacognitive Strategy were the less frequently used ones by the FL and EFL learners (see Table 7(b)).

\section{Conclusions and Discussion}

Conclusions included 1) summary and discussion, 2) implications, and 3) limitations. They were described below:

\subsection{Summary and Discussion}

Two hundred and twenty-four college students in South Taiwan served as subjects of this study, including 209 males and 15 females. They helped to fill out the questionnaire to provide necessary information for the research. In addition to eight items dealing with student's demographic information, the questionnaire contained four parts: Motivation/Attitude Inventory for English Learning (Gardner, 1985), Beliefs about Language Learning Inventory (Horwitz, 1988), Strategy Inventory for Language Learning (Oxford, 1989), and Foreign Language Classroom Anxiety (Horwitz, Horwitz, \& Cope, 1986) (see Table 1). The reliability was $.80, .81, .85, .83, .97$, and .84 for Motivation, Attitude, Motivational Intensity, Beliefs, Strategy, and Anxiety, respectively (see Table 2).

Findings included that first, factors affecting students' English achievement were 1) motivational intensity, 2) strategy use, 3) foreign language learning anxiety, 4) gender, 5) chance for English reading, and 6) chance for English writing. Among them, strategy use was the most important factor related to students' English achievement. It was concluded that in the study, female students were better language learners and students having higher motivational intensity, lower language anxiety, using more language learning strategies, having more chances for language skills of reading and writing tended to have better English achievement (see Table 3). The finding of gender difference was consistent with other studies indicating female students generally had better achievement than male students in language learning (Hou et al., 2015b; Lai, 1977; Leung et al., 1993; Liu, 1973; Oxford et al., 1993); and motivational intensity was supported to be predictive to students' language performance (Hou et al., 2012, 2015b). As for students' reported having more chances for reading and writing were found to be related to their English scores, the possible explanation might be that in many cases in Taiwan, the English tests for students contain more reading and writing than other language skills.

Second, it was found that majority of the students (96.4\%) were motivated to learn English more instrumentally than integratively like many other cases in EFL settings, where students were motivated to learn English for practical reasons, such as to pass exams and to get a good job (Gardner, 1990; Lai, 1977; Hou et al., 2012). But unlike Chen (1989), Gardner \& Lambert (1972), and Lai (1977), who declared that instrumentally motivated learners tended to have better language 
achievement, the findings showed that there was no significant difference in attitude, motivational intensity, beliefs, strategy, anxiety, and English achievement among students with different orientation. The reason might be due to the fact that majority of the students of the study were motivated to learn English more instrumentally (96.4\%), hence the difference between the instrumentally motivated students and their counterparts was not significant.

Third, findings showed that factors affecting strategy use were 1) motivation, 2) attitude, 3) motivational Intensity, 4) beliefs, 5) anxiety, 6) English achievement, and 7) ways to speak English. In other words, students who have strong motivation, positive attitude, higher motivational intensity, strong belief, low anxiety, good English achievement, and like to speak English with foreigners are willing to use more strategies (see Table 4). The findings were consistent with other findings of Prokop (1989); Ehrman \& Oxford, 1989; Oxford, 1986; and Politzer \& McGroarty, 1985 (motivation/orientations); Bialystok, 1983 and Wenden, 1987 (attitude); Oxford \& Nyikos, 1989; and Oxford et al., 1993 (motivational intensity); Nyikos \& Oxford, 1993, Horwitz, 1985, 1988; Oxford, 1990; and Hou et al., 2012, 2015 (beliefs), as well as Horwitz, Horwitz, and Cope, 1986; Horwitz \& Young, 1991a; Hou, 2015; and Hou et al., 2012, 2015a (anxiety). In addition, the findings also revealed that students' English achievement and the ways to speak English with foreigners were relative to their strategy use. It's understandable that success breeds success and students with good achievement will try their best to use more appropriate strategies for better performance, and students who like to communicate with foreigners definitely will use more Social Strategy and Formal-Oral Practice Strategy.

Fourth, it's found that the most frequently used language learning strategy by all students, good language learners and poor language learners was Compensation Strategy for Form A (or Formal-Oral Strategy for Form B). Comparatively, good language learners significantly used more strategies $(\mathrm{M}=3.27, \mathrm{SD}=57)$ than poor language learners $(\mathrm{M}=2.51, \mathrm{SD}=.73)(\mathrm{p}<.01)$. However, the strategy that good language learners used least was Affective Strategy (Form A) or Metacognitive Strategy (Form B), but for poor language learners, the least used strategy was Cognitive Strategy (form A) and Social Strategy (Form B). The findings revealed that both good language learners and poor language learners almost used the same strategies often, but the differences only existed in the means of their language use, in which good language learners had significantly higher mean than that of poor language learners (see Table 5(a) \& Table 5(b)). In other words, good language learners used more strategies than their counterparts, which was consistent with that of Oxford, 1989, 1990a; Rubin, 1975; Hou et al., 2015b.

Fifth, regarding to differences in variables between good language learners and poor language learners, findings showed that except for motivation (orientations), good language learners significantly had more positive attitude ( $\mathrm{p}$ $<.05)$, higher motivational intensity $(\mathrm{p}<.01)$, stronger belief $(\mathrm{p}<.05)$, as well as 
used more strategies $(\mathrm{p}<.01)$ and had less anxiety $(\mathrm{p}<.01)$ (see Table 6$)$.

Last, comparing with other studies of FL, EFL, and ESL, the findings revealed that the language learning strategy which Chinese students (EFL) (Young's 1993 \& the present study) used most frequently is Compensation Strategy, which was not consistent with the findings of Politzer \& Mcgroarty (1985) and Tyacke \& Mendelsohn (1986) who claimed that Asians preferred strategies involving rote memorization and language rules; and Social Strategy for learners of ESL (Oxford et al., 1990) for Form A; while Formal-Oral/Rule Strategy was the most frequently used by learners of FL (Oxford et al., 1989), EFL (Young, 1993), and the present study for Form B. On the contrary, in the study, the strategy that students used least was Affective Strategy, which was quite different from that of ESL (Oxford et al., 1990) and other EFL (Young, 1993), while the least frequently used strategy was Memory Strategy for Form A. Additionally, the study found that the strategy that students used most was Formal-Oral Strategy, which was consistent with the findings of FL (Oxford \& Nyiko, 1989) when American college students learning Russian, French, Spanish, Italian, and German as a foreign language, as well as other EFL (Young, 1993) for Form B. Furthermore, Functional Strategy, Cognitive-Memory Strategy, and Metacognitive Strategy tended to be the less frequently used strategies by learners of FL (Oxford \& Nyiko, 1989), EFL (Young, 1993), and the present study for Form B (see Table 7(a) \& Table 7(b)).

All in all, findings of the study supported the previous studies that strategy use was related to 1) the target language (Chamot, 1993; Chamot \& O'Malley, 1987; Chamot \& Kupper, 1989); 2) the learning situation (Bacon, 1992; Oxford, 1993c; Rubin, 1975); and 3) language learners of national origin/Ethnicity (Politzer \& Mcgroarty, 1985; Tyacke \& Mendelsohn, 1986), gender (Lai, 1977; Leung et al., 1993; Liu, 1973; Oxford et al., 1993), attitude (Bialystok, 1983; Bialystok \& Frohlich's, 1978; Oxford, 1990a; Wenden, 1987); motivational intensity (Oxford \& Nyikos, 1989, 1993); belief (Nyikos \& Oxford, 1993; Oxford \& Nyikos, 1989; Oxford, 1990a); anxiety (Horwitz \& Young, 1991a; Hou et al, 2012, 2015a), as well as language learner's previous success and the chances for reading, writing, and communication with foreigners, all led to good language learners' using more and appropriate strategies.

\subsection{Implications}

Some implications were described below:

First, goal setting and high expectation: motivational Intensity was found to greatly affect both students' English achievement and language learning strategy use. But almost three fourths (74\%) of the students of the study were found to be categorized as Medium Level of Motivational Intensity. That is to say many students needed to increase expectations related to effort in their studies. It was suggested that in curriculum design, a specific, moderately different, challenge, but reachable goal (Good \& Brophy, 1990) should be set in the very beginning. 
In addition, schools should try to provide students and teachers with real language learning environments of FL and ESL, such as English Corner and cross-cultural exchange programs so that students become motivated and use more appropriate strategies for better whole language performance.

Second, awareness of language learning strategies: Appropriate strategies help students learn more efficiently and effectively. Teachers should help students to become aware of the importance of using strategies by letting them know what type of strategies are suitable for them for more effective learning. To raise students' awareness of language learning strategies is a little bit, but it can go a long way (Flaitz, 1995).

Third, strategy training: Language learning strategy can be trained and it works. Teachers should train students to use more appropriate learning strategies, especially strategies found to be used by most good language learners and most appropriate for the individual students.

Last, teachers' readiness: Teachers should be ready for strategy training. Many teachers themselves may not feel comfortable in strategy teaching (Flaitz, 1995). It is suggested that language teachers be motivated to participate in strategy training programs so as to help students afterwards.

\subsection{Limitations}

There were two limitations of the study. First, the sample size didn't have a good balance of males and females (209: 15), though female freshmen were all included in the study then, the findings of gender difference might not be representative to other cases. Second, in comparing the strategy use among learners of FL, ESL, and EFL, some were adopted from the results of Oxford \& Nyiko's, 1989 (FL), Oxford et al.'s, 1990 (ESL), and Young's 1993 (EFL). The future study should consider including the foreign learners to be part of the participants to provide the first hand information.

\section{Conflicts of Interest}

The authors declare no conflicts of interest regarding the publication of this paper.

\section{References}

Albert, R., \& Habo, R. N. (1960). Anxiety in Academic Achievement Situations. Journal of Abnormal and Social Psychology, 10, 207-215. https://doi.org/10.1037/h0045464

Bacon, S. M. (1992). The Relationship between Gender, Comprehension, Processing Strategies, and Cognitive and Affective Response in Foreign Language Listening. The Modern Language Journal, 76, 160-178. https://doi.org/10.1111/j.1540-4781.1992.tb01096.x

Bardwick, J. (1971). Psychology of Women. A Study of Biocultural Conflicts. New York: Harper \& Row.

Bialystok, E. (1983). Some Factors in the Selection and Implementation of Communication Strategies. Applied Linguistics and Language Study, 1983, 100-118.

Bialystok, E., \& Frohlich, M. (1978). Variables of Classroom Achievement in Second 
Language Learning. Modern Language Journal, 62, 327-336.

Carroll, J. B. (1990). Cognitive Abilities in Foreign Language Aptitude: Then and Now. In T. H. Parry, \& C. W. Stansfield (Eds.), Language Aptitude Reconsidered (pp. 17-35). NJ: Prentice Hall Regents.

Carroll, J. B., \& Sapon, S. M. (1959). Modern Language Aptitude Test (MLAT). New York: Psychology Corporation.

Chamot, A. U. (1993). Student Response to Learning Strategy Instruction in the Foreign Language Classroom. Foreign Language Annals, 26, 308-323.

https://doi.org/10.1111/j.1944-9720.1993.tb02288.x

Chamot, A. U., \& Kupper L. (1989). Learning Strategies in Foreign Language Instruction. Foreign Language Annals, 22, 13-24. https://doi.org/10.1111/j.1944-9720.1989.tb03138.x

Chamot, A. U., \& O’Malley, J. M. (1987). The Cognitive Academic Language Learning Approach: A Bridge to the Mainstream. TESOL Quarterly, 21, 227-249. https://doi.org/10.2307/3586733

Chen, L. J. (1989). Some Important Characteristics of Good Language Learners - A Study of Cadets from the Chinese Military Academy. A paper for the promotion of an associate professor. Nanjing: The Chinese Military Academy.

Chesterfield, R., \& Chesterfield, K. B. (1985). Natural Order of Children's Use of Second Language Learning Strategies. Applied Linguistics, 6, 45-59. https://doi.org/10.1093/applin/6.1.45

Ehrman, M., \& Oxford, R. (1989). Effects of Sex Difference, Career Choice, and Psychological Type on Adult Language Learning Strategies. The Modern Language Journal, 73, 1-13. https://doi.org/10.1111/j.1540-4781.1989.tb05302.x

Eysenck, M. W. (1979). Anxiety, Learning and Memory: A Reconceptualization. Journal of Research in Personality, 13, 363-385. https://doi.org/10.1016/0092-6566(79)90001-1

Flaitz, J. (1995). Raising General Awareness of Language Learning Strategies-A Little Bit Goes a Long Way. Hispania, 78, 337-348. https://doi.org/10.2307/345434

Franken, R. E. (1982). Human Motivation. Monterey, CA: Brooks and Cole Publishing Co.

Gardner, R. C. (1979). Social Psychological Aspects of Second Language Acquisition. In H. Giles, \& R. S. Clair (Eds.), Language and Social Psychology (pp. 193-220). Basil: Blackwell.

Gardner, R. C. (1985). Social Psychological and Second Language Learning: The Role of Attitude and Motivation. Baltimore, MD: Edward Arnold.

Gardner, R. C. (1990). Attitudes, Motivation, and Personality as Predictors of Success in Foreign Language Learning. In T. S. Parry, \& C. W. Stansfield (Eds.), Language Aptitude Reconsidered. Englewood Cliffs, NJ: Prentice Hall Regents.

Gardner, R. C., \& Lambert, W. E. (1959). Motivational Variables in Second Language Acquisition. Canadian Journal of Psychology, 13, 266-272. https://doi.org/10.1037/h0083787

Gardner, R. C., \& Lambert, W. E. (1972). Attitude and Motivation in Second Language Learning. Rowley, MA: Newbury House Publishers.

Gay, L. R. (1992). Educational Research: Competencies for Analysis and Application (4th ed.). New York: Macmillan Publishing Company.

Genesee, F. (1983). Bilingual Education of Majority-Language Children: The Immersion Experiments in Review. Applied Psycholinguistics, 4, 1-46.

https://doi.org/10.1017/S0142716400001739 
Good, T. L., \& Brophy, J. E. (1990). Educational Psychology: A Realistic Approach. New York: Longman.

Hagen, A. S. et al. (1994). Learning to Work Smarter in College: The Effects of Strategy Instruction on Attributions to Failure. Paper presented at the American Educational Research Association, New Orleans, April 1994.

Horwitz, E. (1985). Using Student Beliefs about Language Learning and Teaching in the Foreign Language Methods Course. Foreign Language Annals, 18, 333-34. https://doi.org/10.1111/j.1944-9720.1985.tb01811.x

Horwitz, E. (1987). Surveying Students Beliefs about Language Learning. In A. L. Wenden, \& J. Rubin (Eds.), Learner Strategies in Language Learning (pp. 119-129). Englewood Cliffs, NJ: Prentice-Hall.

Horwitz, E. (1988). The Beliefs about Language Learning of Beginning University Students. Modern Language Journal, 72, 182-193. https://doi.org/10.1111/j.1540-4781.1988.tb04190.x

Horwitz, E. K., \& Young, D. J. (1991a). Language Anxiety. Englewood Cliffs, NJ: Prentice Hall.

Horwitz, E. K., \& Young, D. J. (1991b). Preface. In E. K. Horwitz, \& D. J. Young (Eds.), Language Anxiety: From Theory and Research to Classroom Implications (pp. xii-xiv). Englewood Cliffs, NJ: Prentice Hall.

Horwitz, E. K., Horwitz, M. B., \& Cope, J. (1986). Foreign Language Classroom Anxiety. The Modern Language Journal, 70, 125-132. https://doi.org/10.1111/j.1540-4781.1986.tb05256.x

Hou, Y. A. (2015). The Relationship of Multiple Intelligences, Foreign Language Learning Anxiety and English Proficiency-A Case Study of Taiwanese EFL College Students. The International Journal of the Communication and Linguistic Studies, 12, 15-29.

Hou, Y. A., Hou, Y. J, Cheng, H. Y., \& Chung, W. Y. (2015a). Do Learners of Different Foreign Languages Have Different Beliefs and Anxiety-A Case Study of Taiwanese Learners of English and Japanese. The International Journal of the Communication and Linguistic Studies, 13, 67-78.

Hou, Y. A., Lee, F. M., Hou, Y. J, Chung, W. J., \& Cheng, H. Y. (2015b). Taiwanese College Students' Language Learning Strategy Use by Different Levels. International Journal of Arts and Sciences, 8, 231-242.

Hou, Y. J., Lee, F. M., Hou, Y. A., Chung, W. Y., \& Cheng, H. Y. (2012). The Impacts of Teachers' Beliefs on Students' Anxiety about Foreign Language Learning: The East and the West. The International Journal of the Humanities, 9, 245-260.

Jamieson, J. (1992). The Cognitive Styles of Reflection/Impulsivity and Field Independence/Dependence and ESL Success. The Modern Language Journal, 76, 491-501. https://doi.org/10.1111/j.1540-4781.1992.tb05398.x

Lai, P. Y. (1977). Attitude, Motivation and Foreign Language Learning. Studies in English Literature and Linguistics, 3, 85-97.

Larsen-Freeman, D., \& Long, M. H. (1991). An Introduction to Second Language Acquisition Research. New York: Longman.

Leung, J. J. et al. (1993). Gender Differences in Academic Motivational Orientations: American and Chinese Students (pp. 357-861). ERIC Document Resume. ED.

Liu, P. C. (1973). A Study of the Relationships between the Native Chinese Speakers' Spoken English Proficiency and His Attitude, Motivation and Background in Learning English. Unpublished Ph.D. Dissertation, Carbondale, IL: Southern Illinois University. 
MacIntyre, P. D. (1995). How Does Anxiety Affect Second Language Learning? A Reply to Sparks and Ganschow. The Modern Language Journal, 79, 90-99. https://doi.org/10.1111/j.1540-4781.1995.tb05418.x

Mantle-Bromley, C., \& Miller, B. R. (1991). Effects of Multicultural Lessons on Attitudes of Students of Spanish. The Modern Language Journal, 75, 418-424. https://doi.org/10.1111/j.1540-4781.1991.tb05376.x

Nyikos, M. (1990). Sex-Related Differences in Adult Language Learning: Socialization and Memory Factors. The Modern Language Journal, 74, 273-286. https://doi.org/10.1111/j.1540-4781.1990.tb01063.x

Nyikos, M., \& Oxford, R. (1993). A Factor Analytic Study of Language-Learning Strategy Use: Interpretations from Information-Processing Theory and Social Psychology. The Modern Language Journal, 77, 11-22. https://doi.org/10.1111/j.1540-4781.1993.tb01940.x

O’Malley, J. M. et al. (1985). Learning Strategies Used by Beginning and Intermediate ESL Students. Language Learning, 35, 21-44. https://doi.org/10.1111/j.1467-1770.1985.tb01013.x

Oxford, R. (1993). Instructional Implications of Gender Differences in Second/Foreign Language (L2) Learning Styles and Strategies. Applied Language Learning, 4, 65-94.

Oxford, R. D., \& Cohen, A. D. (1992). Language Learning Strategies: Crucial Issues of Concepts and Classification. Applied Language Learning, 3, 1-35.

Oxford, R. et al. (1993). Learning a Language by Satellite Television: What Influences Student Achievement? System, 21,31-48. https://doi.org/10.1016/0346-251X(93)90005-2

Oxford, R. L. (1986). Development and Psychometric Testing of the Strategy Inventory for Language Learning (SILL). ARI Technical Report 728. Alexandria, VA: US Army Research Institute for the Behavioral and Social Sciences.

Oxford, R. L. (1989). Use of Language Learning Strategies: A Synthesis of Studies with Implications for Strategy Training. System, 17, 235-247. https://doi.org/10.1016/0346-251X(89)90036-5

Oxford, R. L. (1990a). Language Learning Strategies: What Every Teacher Should Know. New York: Newbury House/Harper \& Tow.

Oxford, R. L. (1990b). Missing Link: Evidence from Research on Language Learning Styles and Strategies. In J. E. Alatis (Ed.), Georgetown University Round Table on Language and Linguistics (pp. 438-458). Washington DC: Georgetown University Press.

Oxford, R. L. (1990c). Styles, Strategies, and Aptitude: Connections for Language Learning. In T. S. Parry, \& C. W. Standsfield (Eds.), Language Aptitude Reconsidered (pp. 67-125). Upper Saddle River, NJ: Prentice Hall Regents.

Oxford, R. L. (1992). Language Learning Strategies in a Nutshell: Update and ESL Suggestions. TESOL Journal, 1992/1993, 18-22.

Oxford, R. L. (1993a). Instructional Implications of Gender Differences in Second/Foreign Language (L2) Learning Styles and Strategies. Applied Language Learning, 4, 65-94.

Oxford, R. L. (1993b). Progress in Tertiary Content-Based ESL Instruction. TESL Canada Journal/Revue TESL DU Canada, 11, 75-97.

Oxford, R. L. (1993c). Research on Second Language Learning Strategies. Annual Review of Applied Linguistics, 13, 175-187.

Oxford, R. L. et al. (1990). Strategy Training for Language Learners: Six Situational Case Studies and a Training Model. Foreign Language Annals, 22, 197-216. 
https://doi.org/10.1111/j.1944-9720.1990.tb00360.x

Oxford, R. L., \& Ehrman, M. (1993). Second Language Research on Individual Differences. Annual Review of Applied Linguistics, 13, 188-205. https://doi.org/10.1017/S0267190500002464

Oxford, R. L., \& Nyikos, M. (1989). Variables Affecting Choice of Language Learning Strategies by University Students. The Modern Language Journal, 73, 291-300. https://doi.org/10.1111/j.1540-4781.1989.tb06367.x

Oxford, R. L., Lavine, R. Z., \& Crookall, D. (1989). Language Learning Strategies, the Communicative Approach, and Their Classroom Implications. Foreign Language Annals, 22, 29-39. https://doi.org/10.1111/j.1944-9720.1989.tb03139.x

Oxford, R., Park-Oh, Y., Ito, S., \& Sumrall, M. (1993). Japanese by Satellite: Effects of Motivation, Language Learning Styles and Strategies, Gender, Course Level, and Previous Language Learning Experience on Japanese Language Achievement. Foreign Language Annals, 26, 359-371. https://doi.org/10.1111/j.1944-9720.1993.tb02292.x

Politzer, R. (1983). An Exploratory Study of Self Reported Language Learning Behaviors and Their Relation to Achievement. Studies in Second Language Acquisition, 6, 54-68. https://doi.org/10.1017/S0272263100000292

Politzer, R., \& McGroarty, M. (1985). An Exploratory Study of Learning Behaviors and Their Relationship to Gains in Linguistic and Communicative Competence. TESOL Quarterly, 19, 103-123. https://doi.org/10.2307/3586774

Prokop, M. (1989). Learning Strategies for Second Language Users: An Analytical Approach with Case Studies. Lewiston, NY: The Edwin Mellen Press.

Rubin, J. (1975). What the "Good Language Learner" Can Teach Us? TESOL Quarterly, 9, 41-51. https://doi.org/10.2307/3586011

Schiefele, U., \& Wild, K. P. (1994). Motivational Predictors of Strategy Use under Course Grades. Paper presented at the Annual Meeting of the AERA, New Orleans, April 1994.

Scovel, T. (1978). The Effect of Affect on Foreign Language Learning: A Review of the Anxiety Research. Language Learning, 28, 129-142. https://doi.org/10.1111/j.1467-1770.1978.tb00309.x

Skehan, P. (1991). Individual Differences in Second Language Learning. Studies in Second Language Acquisition, 13, 275-298. https://doi.org/10.1017/S0272263100009979

Titone, R. (1990). A Psycho-Sociolinguistic Perspective in EFL Learning: The Role of Attitude a Dynamic Factor. Paper presented at The World Congress of Applied Linguistics, sponsored by the International Association of Applied Linguistics (9th, Thessaloniki, Greece, 15-21 April 1990) ERIC Document Resume, ED, 326-073.

Tobias, S. (1983). Anxiety and Cognitive Processing of Instruction. https://www.researchgate.net/publication/235059775

Trylong, V. L. (1987). Aptitude, Attitudes, and Anxiety: A Study of Their Relationships to Achievement in the Foreign Language Classroom. Dissertation of Purdue University.

Tyacke, M., \& Mendelsohn, D. (1986). Student Needs: Cognitive as Well as Communicative. TESL Canada Journal, Special Issue 1, 171-183.

Wenden, A. (1987). Metacognition: An Expanded View on the Cognitive Abilities of L2 Learners. Language Learning, 37, 573-597.

https://doi.org/10.1111/j.1467-1770.1987.tb00585.x

Wittrock, M. (Ed.) (1977). Learning and Instruction. Berkeley, CA: McCutchan.

Young, D. J. (1993). Processing Strategies of Foreign Language Readers: Authentic and 
Edited Input. Foreign Language Annals, 26, 451-468.

https://doi.org/10.1111/j.1944-9720.1993.tb01180.x

Young, D. J. (1995). Raising General Awareness of Language Learning Strategies: A Little Bit Goes a Long Way. Hispania, 78, 337-348. https://doi.org/10.2307/345434 